\title{
Phenolic compounds and their relationship to in vitro digestibility of sorghum leaves of bird-resistant and non-bird-resistant varieties
}

\author{
I. Mueller-Harvey ${ }^{1}$, J. D. Reed ${ }^{2}$, M. S. Dhanoa ${ }^{1}$ and A. B. McAllan ${ }^{1}$ \\ ${ }^{1}$ AFRC Institute of Grassland and Environmental Research, Hurley SL6 5LR \\ ${ }^{2}$ Department of Meat and Animal Science, University of Wisconsin-Madison, 1675 Observatory Drive, Madison, \\ Wisconsin 53706-1284, USA
}

\section{Introduction}

Sorghum stover is used as a food for ruminants in many developing countries. However, the stover can contain large amounts and a great diversity of phenolic compounds (Butler, 1989) which may limit its nutritional value by inhibiting the digestion of the structural carbohydrates in the rumen. Recent studies have shown that large differences exist between varieties with respect to their overall phenolic concentration and in vitro dry matter digestibility (Reed, Tedla and Kebede, 1987).

The aim of this work was to compare the phenolic composition of sorghum leaves from different varieties in more detail and to relate the findings with digestibility parameters.

\section{Material and methods}

Twenty-four sorghum varieties were grown at Melkasa, Debre Zeit and Dukam, Ethiopia, using a completely randomized-block design and were harvested at grain maturity (see Mueller-Harvey and Dhanoa (1991) for further details). Leaves were separated into leaf blade (LB) and leaf sheath (LS) fractions.

\section{Results}

Phenolic compounds in leaves of BR and NBR varieties

The composition of phenolics was clearly different between LB and LS in all varieties (Figure 1). Varietal differences were greatest in LS, where a clear distinction could be made between bird-resistant (BR) and non-bird-resistant (NBR) varieties (Figure 2).

Apigenin, luteolin and their 7-o-glucosides accounted for the most prominent peaks in the highperformance liquid chromatography (HPLC) separations of phenolics from LB of BR- and NBR- varieties and from LS of NBR-varieties (Figure 1). However, LS of BR-varieties contain apigeninidin and luteolinidin derivatives (Figures 1 and 2). Several other compounds were also detected, e.g. butin, p-coumaric acid and derivatives of chalcone and flavanone/dihydroflavonol.

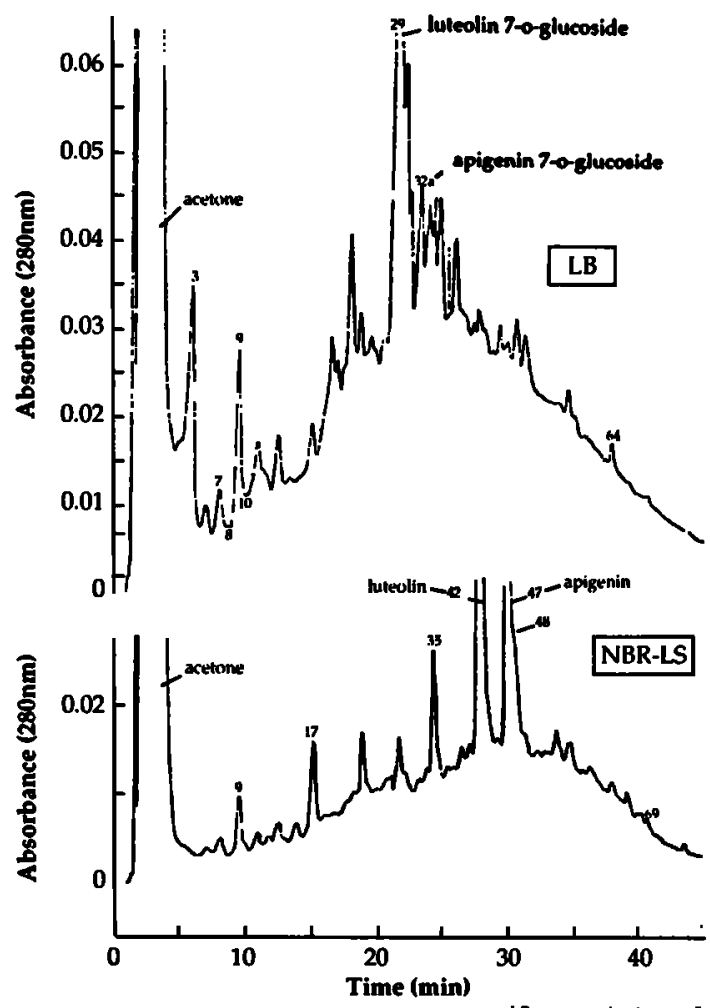

Figure 1 Typical HPLC separations (recorded at $280 \mathrm{~nm}$ ) of phenolics extracted from bird-resistant (BR) or non-birdresistant (NBR) leaf blade (LB) and from NBR-leaf sheath (LS) of sorghum varieties. 


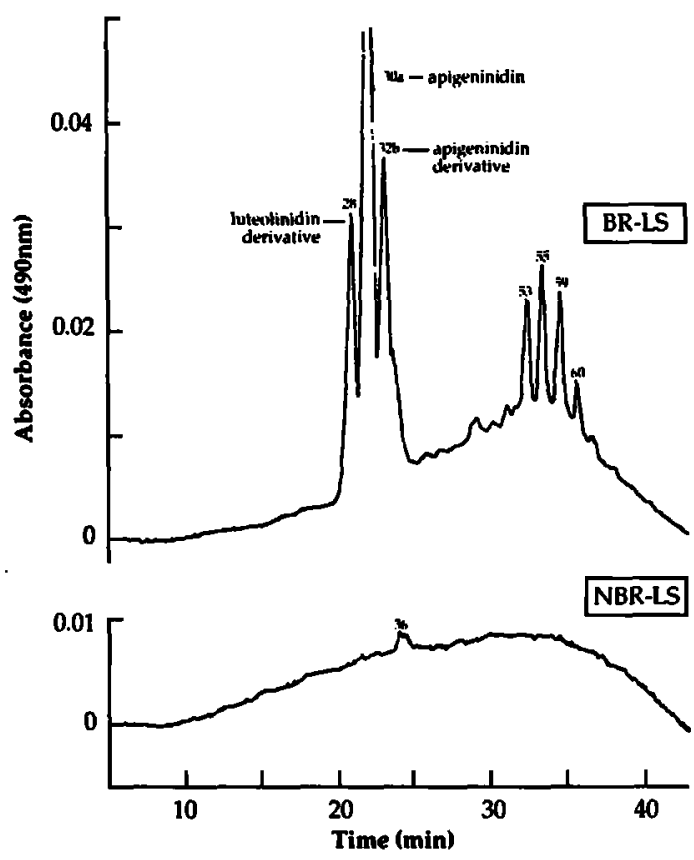

Figure 2 HPLC chromatograms (recorded at $490 \mathrm{~nm}$ ) illustrating the differences between leaf sheath (LS) phenolics extracted from bird-resistant (BR) and non-birdresistant (NBR) varieties.

Biosynthesis of flavonoids appears to diverge at the flavanone/dihydroflavonol stage between BR- and NBR-sorghum varieties.

Phenolic composition in relation to in vitro digestibilities Several negative correlations were found between HPLC peak heights and in vitro digestibilities. These were highly significant with butin and significant with several luteolin derivatives. Butin in turn was highly negatively correlated with colorimetric measurements of 3-desoxyanthocyanidins. This may suggest that butin, rather than the 3desoxyanthocyanidins as previously reported (Reed et al., 1987), is implicated in reducing dry-matter digestibility.

Selecting for varieties with leaves rich in apigenin-, rather than luteolin-type compounds should enhance the digestibility of their sorghum crop residues.

\section{Conclusions}

Leaf sheaths of BR- and NBR-sorghum varieties contain different types of phenolic compounds. One of these phenolics, butin, occurs only in BR-varieties and was highly significantly correlated to in vitro digestibility of dry matter.

It is suggested that selecting varieties for lower concentrations of butin and luteolin derivatives should increase digestibility.

\section{Acknowledgements}

Thanks are due to Dr Y. Yebede, Mr P. M. S. Blackwell, the International Livestock Centre for Africa (Addis Ababa), and the Overseas Development Administration for financial support.

\section{References}

Butler, L. G. 1989. Sorghum polyphenols. In Toxicants of plant origin. IV. Phenolics (ed. P. R. Cheeke), pp. 95-121. CRC Press.

Mueller-Harvey, I. and Dhanoa, M. S. 1991. Varietal differences amongst sorghum crop residues in relation to their phenolic HPLC-fingerprints and responses to different environments. Journal of Science of Food and Agriculture 57: 199-216.

Reed, J. D., Tedla, A. and Kebede, Y. 1987. Phenolics, fibre and fibre digestibility in the crop residue from bird and non-bird resistant sorghum varieties. Iournal of Science of Food and Agriculture 39: 113-121. 